\title{
COMO O GÊNERO INFLUENCIA NOS CÁLCULOS \\ E RELAÇÕES EPISTÊMICAS
}

\section{HOW GENDER INFLUENCES CALCULATIONS AND EPISTEMIC RELATIONS}

\author{
Torquato Augusto Viglioni ${ }^{1}$
}

Resumo: Na obra "Epistemic's Injustice" de Miranda Fricker são desenvolvidas as ideias de injustiças epistêmicas e virtudes epistêmicas a partir de uma concepção de justiça que pressupõe que o comum são as injustiças e a justiça é a correção daquelas. Assim, o normal seriam as relações epistêmicas injustas e a correção seriam as virtudes. Entretanto ao descrever e conceitualizar as injustiças epistêmicas a autora as diferencia e as separa em injustiças testemunhais e hermenêuticas, apesar de ambas se originarem e se fundarem sobre as relações de poder social. A injus- tiça testemunhal é conceitualizada como um cálculo epistêmico injusto influenciado por preconceitos identitários derivados do poder social. A injustiça hermenêutica é conceitualizada como uma lacuna estrutural social, isto é, inserido na base social. Ao conceitualizar a virtude epistêmica a filósofa utiliza a ideia de justiça corretora das injustiças, assim, cada virtude é exercida de modo a corrigir e na medida das injustiças que aquelas visam. As injustiças testemunhas seriam corrigidas por ações virtuosas no âmbito testemunhal através do ouvinte virtuoso que seria sensí-

1 Graduado em Filosofia pela UFSC

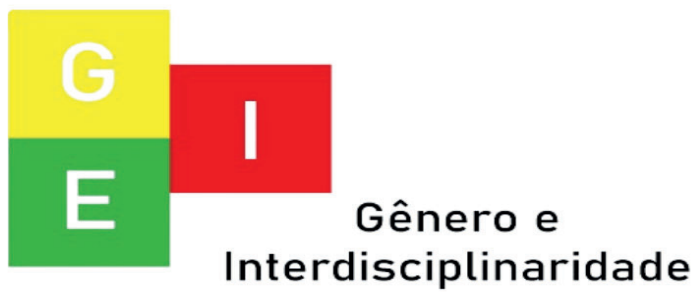


ISSN: 2675-7451

Vol. 02 - n 06 - ano 2021

Editora Acadêmica Periodicojs

vel às relações sociais, ao dever

ético e, assim, teria condições de atribuir credibilidade ao falante de modo justo. Entretanto, apesar de defender a dosimetria das virtudes epistêmicas e ressaltar que é preciso uma ação política de grupo para mudança social, a filósofa defende que o papel ético primário de justiça hermenêutica é de mitigar o impacto negativo da injustiça hermenêutica sobre a falante. A partir das concepções da autora que estruturam as injustiças epistêmicas - o poder social - é possível fazer um elo com Silvio Almeida, esse elo permite a construção de uma argumentação sobre como o gênero é um fator que influencia as relações epistêmicas. A partir dessa premissa é possível inferir que a descredibilização ou a credibilização excessiva é utilizada como meio/modo de dominação e perpetuação social.

Palavras-chave: Gênero; Injustiça epistêmica; Poder social; Estrutural; Virtude Epistêmica.

Abstract: In the work "Epistemic's Injustice" by Miranda Fricker, the ideas of epistemic injustices and epistemic virtues are developed from a conception of justice that assumes that injustices are common and justice is their correction. Thus, the normal would be the unjust epistemic relationships and the correction would be the virtues. However, when describing and conceptualizing epistemic injustices, the author differentiates and separates them into testimonial and hermeneutic injustices, despite the fact that both originate and are based on relations of social power. Witness injustice is conceptualized as an unfair epistemic calculation influenced by

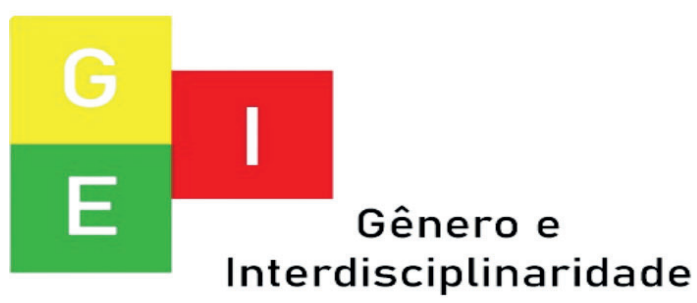


Vol. 02 - n 06 - ano 2021

Editora Acadêmica Periodicojs

identity prejudices derived from social power. Hermeneutic injustice is conceptualized as a social structural gap, that is, inserted in the social base. When conceptualizing the epistemic virtue, the philosopher uses the idea of correcting justice of injustices, thus, each virtue is exercised in order to correct and to the extent of the injustices that they aim at. Witness injustices would be corrected by virtuous actions in the witness sphere through the virtuous listener who would be sensitive to social relations, to ethical duty and, thus, would be able to give credibility to the speaker in a fair way. However, despite defending the dosimetry of epistemic virtues and emphasizing that group political action is needed for social change, the philosopher argues that the primary ethical role of hermeneutic justice is to mitigate the negative impact of hermeneutic injustice on the speaker. Based on the author's conceptions that structure epistemic injustices - social power - it is possible to make a link with Silvio Almeida, this link allows the construction of an argument about how gender is a factor that influences epistemic relations. From this premise, it is possible to infer that discrediting or excessive credibility is used as a means/mode of domination and social perpetuation.

Keywords: Gender; Epistemic injustice; Social power; Structural; Epistemic Virtue.

\section{Injustiças Epistêmicas}

O conceito de injustiça pensado pela filosofia política é derivado do conceito de justiça, nessa corrente a injustiça é conceitualizada como uma ausência

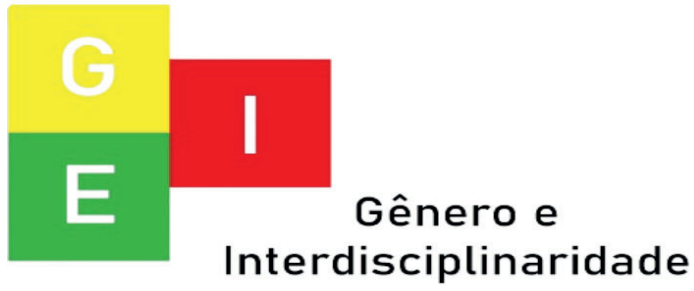


Vol. 02 - n 06 - ano 2021

Editora Acadêmica Periodicojs

de justiça, permitindo inferir que

a justiça é o normal e a injustiça, a anormalidade. Miranda Fricker, todavia, quer criticar tal suposição. Diz ela: o entendimento sobre Justiça tem outra conotação no meio epistêmico, as práticas epistêmicas são exercidas por sujeitos necessariamente inseridos no mundo, tal condição implica que estereótipos e preconceitos identitários interferem diretamente nessas práticas, promovendo, assim, normas epistêmicas injustas. Fricker cita Skhal sobre a normalidade da injustiça: $[\mathrm{H}]$ á um modo normal de pensar a justiça, que Aristóteles não inventou, mas certamente codificou e imprimiu para sempre em todas as nossas mentes. Esse modelo normal de justiça não ignora a injustiça, mas tende a reduzi-la a um prelúdio ou a uma rejeição e quebra da justiça, como se a injustiça fosse uma anormalidade surpreendente. (FRICKER, 2007, p. 279)

Por isso, é importante para Fricker iniciar a investigação sobre este problema, destacando que a regularidade das práticas epistêmicas promove injustiças. Kuhnen ressalta bem a missão que a filósofa quer cumprir no seguinte trecho:

Fricker, no entanto, entende que a injustiça pode ser algo tão constante nas diferentes dimensões da vida humana de modo que assume uma condição de normalidade e subsequente invisibilidade. Dessa forma, investigar e refletir sobre a injustiça em suas diversas facetas, preenchendo as lacunas do conhecimento

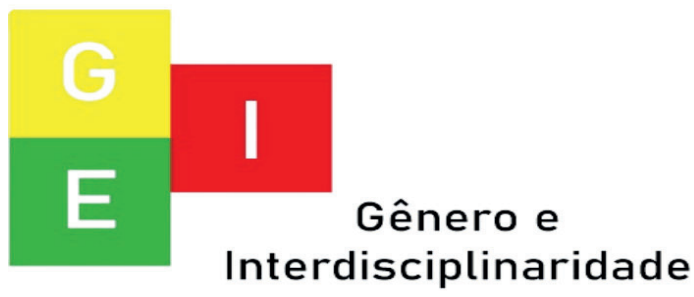


Vol. 02 - n 06 - ano 2021

Editora Acadêmica Periodicojs

sobre ela, pode ser, muitas vezes, o único modo de torná-la evidente, e, assim, abrir a porta que conduz à justiça. (KUHNEN, T. FRICKER, 2013, p. 633)

As injustiças epistêmicas são faltas cometidas com alguma pessoa e/ou grupos em suas capacidades de fornecedores de conhecimento ou na capacidade como sujeitos de compreensão social. Isso acontece comumente a diversos grupos sociais que não recebem a devida credibilidade de testemunho que pode ser fonte de conhecimento. Este é o aspecto ético das injustiças epistêmicas, como aponta Kunhem:

As injustiças epistêmicas têm um fundo ético na produção de conhecimento pelos sujeitos socialmente situados tem sua dimensão ética traduzida na forma da jus- tiça e da injustiça (p. vii). O problema ético da injustiça afeta os seres humanos enquanto sujeitos epistêmicos dotados da capacidade de produzir, possuir e repassar conhecimento sobretudo através da prática do testemunho. (KUHNEN, T. FRICKER, 2013, p. 627)

As injustiças epistêmicas são caracterizadas de duas formas: testemunhal e hermenêutica, como serão descritas nos tópicos subsequentes. Antes se faz necessário apresentar a fundamentação teórica a partir da qual a filósofa constrói sua tese.

Fricker começa trazendo o conceito de poder social e destaca como este influencia as relações epistêmicas entre os indivíduos sociais. Assim, este poder é "uma capacidade socialmente situada para controlar as

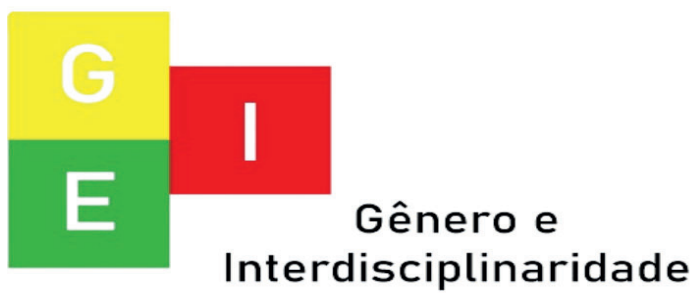


Vol. 02 - n 06 - ano 2021

Editora Acadêmica Periodicojs

ações dos outros, onde essa capa-

cidade pode ser exercida (ativa ou passivamente) por determinados agentes sociais ou, alternativamente, pode operar puramente de modo estrutural." Para se entender o poder agindo nas relações sociais se faz necessário entender o que é o poder identitário e como esses - apesar de independentes-se correlacionam na sociedade. Exemplificando-se melhor:

Pode haver operações de poder que dependem de agentes possuírem concepções de identidade social compartilhadas - concepções vivas na imaginação social coletiva que governam, por exemplo, o que é ou significa ser mulher ou homem, ou o que é ou significa ser gay ou hetero, jovem ou velho, e assim por diante. Sempre que há uma operação de poder que depende, em algum grau significativo, de tais concepções imaginativas compartilhadas de identidade social, então o poder identitário está em ação. (FRICKER, 2007, p. 29)

Esse poder identitário enquanto poder social - pode ser exercido por agente(s) ou de modo estrutural, o fato é que ele pode influenciar positiva ou negativamente, isto é, tanto a favor dos agentes afetados quanto contra eles. Tal poder, segundo Fricker, é parte integrante do mecanismo de troca testemunhal, operação básica das práticas epistêmicas, que são implicadas por estereótipos em suas avaliações sobre a credibilidade de um testemunho. Porém, o estereótipo carrega um preconceito que é forjado pelos poderes sociais e identitários, resultando em uma disfunção epis-

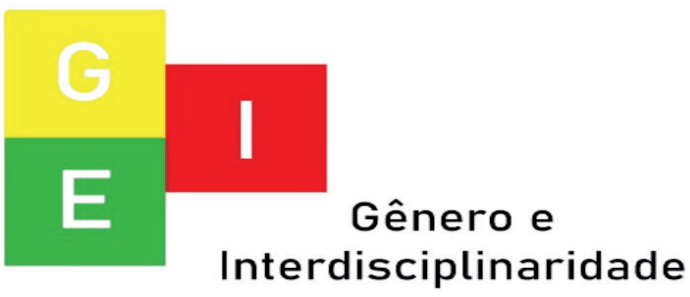


Vol. 02 - n 06 - ano 2021

Editora Acadêmica Periodicojs

têmica. Diante desse quadro, damenta a injustiça é justamenfaz-se necessário abordar agora te uma economia epistêmica o conceito de injustiça testemu- que atribui pouca ou nenhuma nhal. credibilidade a indivíduos que carregam estereótipos identitá-

\subsection{Injustiça Testemunhal} rios, fazendo com que sua participação nas práticas de conhe-

O tipo de injustiça testemunhal acontece quando $\mathrm{o}$ preconceito incide na capacidade de um sujeito de comunicar conhecimento, por conta de uma atribuição deficitária de credibilidade por parte do ouvinte. Por conta do preconceito de identidade, a pessoa que fala é vista como digna de menos crédito como fonte de testemunho, por exemplo: uma mulher, por mais conhecedora sobre determinado assunto, não é credibilizada pelo ouvinte sobre aquilo que é especialista, em razão do preconceito do ouvinte.

$\mathrm{Na}$ injustiça epistêmica de tipo testemunhal o que fun- cimento seja prejudicada ou até completamente impossibilitada. A economia epistêmica, que é a nossa prática coletiva de atribuir credibilidade e autoridade epistêmica a pessoas de uma comunidade, estaria disfarçando, então, a estrutura de poder político nas práticas epistêmicas. Kuhnen ressalta: "Normalmente a injustiça testemunhal aparece como parte de um conjunto mais amplo de injustiças sociais persistentes e sistemáticas que os indivíduos pertencentes a grupos destituídos de poder social, a exemplo de negros, gays e mulheres sofrem." (KUHNEN, 2013, p. 630).

Fricker defende ainda

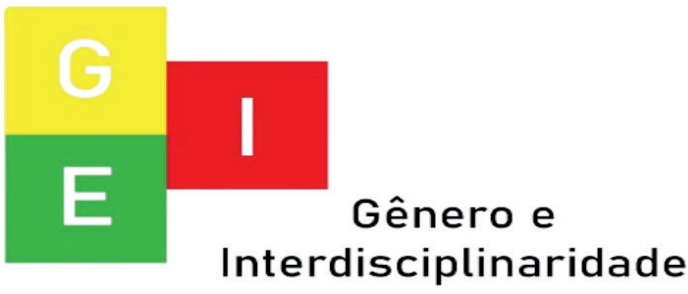


ISSN: 2675-7451

Vol. 02 - n 06 - ano 2021

Editora Acadêmica Periodicojs

que a injustiça testemunhal tende à persistência porque as concepções imaginativas de identidade social, que figuram nos preconceitos rastreadores - estes que rastreiam estereótipos identitários para atribuir credibilidade a um indivíduo - relevantes, provavelmente são características duradouras do imaginário social. (FRICKER, 2007, p. 54)

Um bom exemplo para demonstrar isso é o roteiro de Minghella para The Talented Mr. Ripley, citado pela filósofa. Nesse romance, Marge tenta dizer ao seu sogro que desconfia de Ripley sobre o assassinato de seu marido; o sogro, por sua vez, atravessado por preconceitos identitários, a silencia dizendo que "homens não contam tudo a suas esposas" e ainda completa dizendo que "existe intuição feminina e existem fatos", isto é, comete a injustiça testemunhal sobre Marge. Apesar do interesse em saber quem matou seu filho, o sogro carrega com preconceitos sistêmicos sobre mulheres. Isto é, descredibiliza injustamente sua nora, apesar de ela estar correta, por um preconceito estrutural sobre mulheres. Kuhnen ressalta as consequências da injustiça testemunhal cometidas sobre o falante, apontadas por Fricker:

Todavia, o erro nesse tipo de julgamento não tem apenas dimensão epistêmica, mas também ética: causa-se um dano ético primário a uma capacidade essencial dos seres humanos, qual seja, a capacidade de conhecer e de transmitir conhecimento. A dimensão primária do dano atinge a própria dignidade humana, uma vez que o erro ético tem um significado social cujo efeito é considerar o "sujei-

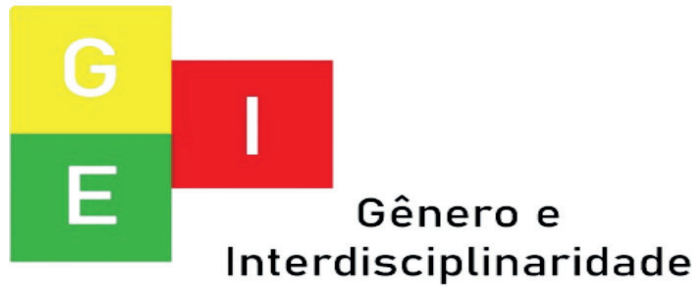


ISSN: 2675-7451

Vol. 02 - n 06 - ano 2021

Editora Acadêmica Periodicojs

to menos que um ser humano completo" (p. 44). O dano sofrido na injustiça epistêmica tem ainda uma dimensão secundária, pois envolve uma gama de possíveis desvantagens subsequentes à injustiça primária. $\mathrm{O}$ sujeito pode ser profundamente afetado em diferentes dimensões de sua vida - econômica, educacional, profissional, sexual, legal e política -, de modo a impedi-lo de desenvolver-se plenamente enquanto pessoa. (KUHNEN, 2013, p. 630).

Essas consequências são graves para a autodeterminação desses falantes, no exemplo citado anteriormente, percebe-se que Marge sofre uma injustiça testemunhal por preconceitos inseridos nas estruturas sociais.
Esse é um caso que demonstra como fenômenos sociais tem um fundo epistêmico.

\subsection{Injustiça Hermenêutica}

Outro tipo de injustiça epistêmica é a Hermenêutica, essa está mais entranhada nas dinâmicas epistêmicas, na maioria das vezes se faz necessária uma análise minuciosa sobre determinados conceitos e situações. Por exemplo, quando há casos em que uma marginalização política e social obscurece a expressão das experiências desses grupos marginalizados. Isto é, esses grupos ou pessoas não conseguem expressar de maneira inteligível suas experiências sociais a outras pessoas devido a algumas lacunas.

É importante salientar que, para Fricker, tal tipo de injustiça epistêmica é estrutural e

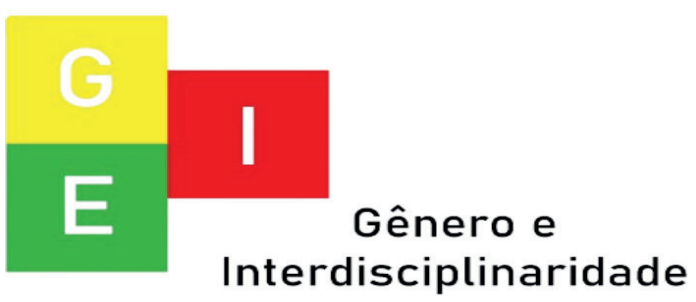


Vol. 02 - n 06 - ano 2021

Editora Acadêmica Periodicojs

não possui necessariamente um perpetrador. Fricker afirma ter se inspirado para a elaboração dessa ideia na discussão do conceito de "poder", de Michel Foucault, que "atua" como uma rede, um nexo de forças: as operações do poder seriam puramente estruturais e, portanto, sem sujeito. (FRICKER, 2007, p. 11) Pode-se perceber que os poderes que afetam as práticas epistêmicas e sociais estão concebidos dentro dessa inspiração, isto é, como um fenômeno estrutural que engloba culturas em sua totalidade.

Fricker apresenta o caso de Carmita Wood como exemplo que será usado para explicar a injustiça hermenêutica. Carmita sofria assédio sexual em seu local de trabalho, mas naquela época a estrutura da sociedade carecia de termos e de juízos sobre o que era assédio sexual. "A falta de entendimento adequado da experiência das mulheres em relação ao assédio sexual era uma desvantagem coletiva mais ou menos compartilhada por todos." (FRICKER, 2007, p. 243) Isto é, nem o próprio assediador tinha o completo entendimento sobre o que ele estava fazendo, no sentido em que aquela estrutura era comum e replicada de modo estrutural. Apesar de não implicar na inocência do assediador, deve ser salientado o fato desta ser uma injustiça estrutural devido à ausência de entendimento e mesmo de vocabulário socialmente compartilhado sobre as experiências vividas por determinados grupos e indivíduos

A injustiça hermenêutica, assim como a testemunhal, gera uma marginalização epistêmica; entretanto a hermenêutica é mais difícil de se detectar porque é resultado das lacunas epistêmicas estruturalmente situ-

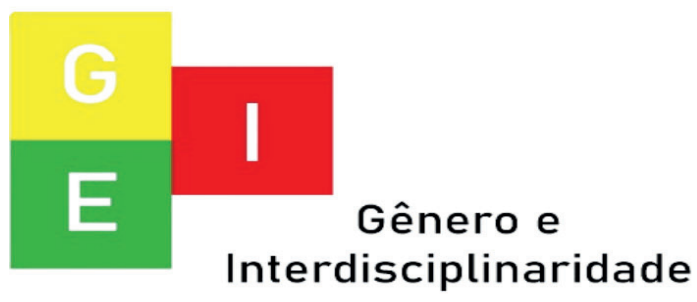


adas na sociedade, por conta de preconceitos discriminatórios de grupos e indivíduos. Geralmente, quando há uma participação hermenêutica desigual em relação a algumas áreas significativas da experiência social, ou seja, quando grupos que detêm poderes identitários e sociais distintos, os mais favorecidos são os criadores e reprodutores de conceitos e ferramentas utilizadas nas práticas epistêmicas, em virtude disso, grupos menos favorecidos têm suas experiências obscurecidas pela falta de conceitos e ferramentas que deem significado às suas vivências.

Os membros do grupo desfavorecido muitas vezes são também marginalizados hermeneuticamente. Essa noção de marginalização é moral-política, indicando subordinação e exclusão de alguma prática que teria valor para o participante.
Fricker afirma que marginalização hermenêutica é sempre uma forma de impotência: estrutural ou pontual. (FRICKER, 2007, p. 247) O resultado é que o sujeito ou o grupo hermeneuticamente marginalizado é impedido de gerar significados relativos sobre algumas áreas do mundo social. Percebe-se aqui um paralelo com a injustiça testemunhal em que a marginalização pode ser afetada por determinadas áreas, inclusive a atmosfera socioeconômica, porém não necessariamente afetar o gênero, o contrário também pode acontecer.

De modo geral, a injustiça que afeta o caso de Carmita, sobre as mulheres em geral, segundo a definição de Fricker é "a injustiça de ter uma área significativa da sua experiência social obscurecida do entendimento coletivo devido à marginalização hermenêutica persistente e abran-

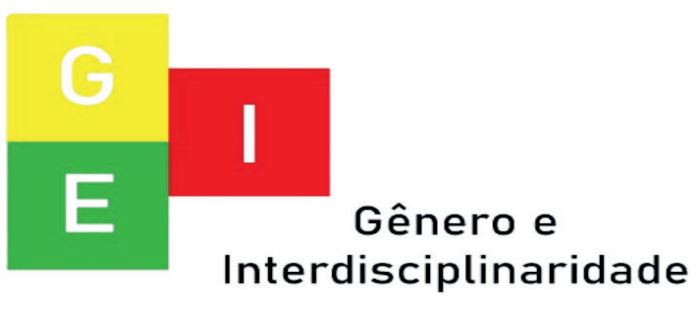


ISSN: $2675-7451$

Vol. 02 - n 06 - ano 2021

Editora Acadêmica Periodicojs

gente.” (FRICKER, 2007, p. 249)

Convém evidenciar, essa margi-

2. Virtude Epistêmica

nalização acompanha o sujeito através de uma série de atividades sociais, nesse caso ser mulher é uma condição de marginalização em várias áreas, assim como na injustiça testemunhal como na hermenêutica. Nesse contexto, Kuhnen aponta que "esse tipo de marginalização resulta o preconceito de identidade estrutural, que também possui uma dimensão ética" . (KUHNEN, 2013, p. 634) Fricker explica que o preconceito estrutural gerado por esse tipo de injustiça é essencialmente discriminatório. Assim, a filósofa define a injustiça hermenêutica como: "a injustiça de ter alguma área relevante da experiência social obscurecida pela falta de entendimento coletivo devido à marginalização hermenêutica" (FRICKER, 2007, p. 158)

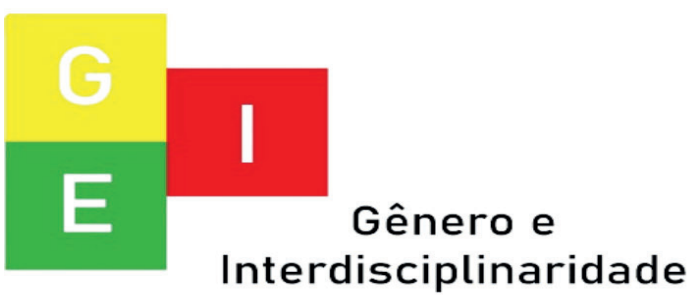
isto é, ela vai variar de acordo com a injustiça cometida. Se a injustiça for testemunhal, tal virtude vai aparecer como forma de corrigir a falta de credibilidade por parte do ouvinte. Se a injustiça for hermenêutica, o processo será mais complexo pois ela está 
Vol. 02 - n 06 - ano 2021

Editora Acadêmica Periodicojs

inserida de modo sistemática/estrutural na sociedade.

O ouvinte virtuoso visa uma sensibilidade sobre os testemunhos de modo que: as libertações da sensibilidade de um indivíduo, então, são moldadas por um conjunto de atitudes interpretativas e motivacionais de fundo, que são herdadas passivamente da comunidade ética, mas depois refletidas ativamente e vividas de uma ou outra maneira pelo indivíduo reflexivo. $\mathrm{O}$ ouvinte virtuoso, portanto, deve estar consciente de como a relação entre sua identidade social e a da falante está impactando a inteligibilidade do que a falante está dizendo e como está dizendo.

As injustiças hermenêuticas necessitam de sistemas para a sua correção. Segundo a filósofa, pode-se amenizar em alguns aspectos com recursos testemunhais, como exemplo, o ouvinte virtuoso. Em contextos hermenêuticos, então, o julgamento de credibilidade do ouvinte responsável é uma avaliação do grau em que o que é dito faz sentido - o grau em que é uma interpretação verossímil. Agora, nos casos em que os esforços da falante são dificultados por uma injustiça hermenêutica, o ouvinte virtuoso registra isso e faz concessões, para que seu julgamento inicialmente de baixa credibilidade seja revisado para cima para compensar o obstáculo.

Para uma real mudança e correção nas estruturas da sociedade, no entanto, essa virtude tem de ser inserida nas bases estruturais. A pensadora explana sua reflexão animadora de como a virtude deve ser agenciada: Mudar as relações desiguais de poder que criam as condições para a injustiça hermenêutica (a saber, a marginalização herme-

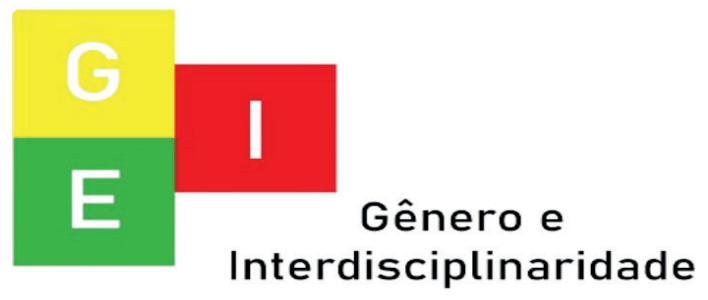


ISSN: 2675-7451

Vol. 02 - n 06 - ano 2021

Editora Acadêmica Periodicojs

nêutica) requer mais do que qualquer conduta individual virtuosa; é preciso ação política de grupo para mudança social. O papel ético primário da virtude da justiça hermenêutica permanece, portanto, um de mitigar o impacto negativo da injustiça hermenêutica sobre a falante.

A partir do exposto fica claro o que as virtudes epistêmicas visam combater e minimizar. Cabe também ressaltar que Fricker percebe que, apesar de necessárias, as virtudes epistêmicas no âmbito individual têm pouca eficiência para a sociedade, portanto, apesar de não especificar qual o formato e quais as medidas devem ser tomadas, Fricker sugere que as virtudes devem ser estendidas paras as instituições, assim, dependem de políticas institucionalizadas contra preconceitos implícitos.

\section{O lado epistêmico das injus- tiças sociais}

As relações sociais entre indivíduos e grupos são derivadas de bases históricas, institucionais e estruturais, que são necessariamente confluentes entre si, ou seja, as relações nunca são derivadas apenas de uma ou outra base, mas sempre do movimento conjunto desses alicerces.

Convém evidenciar que a História permite demonstrar a origem das injustiças sociais que afetam as estruturas, essas são replicadas pelas instituições. Para demonstrar isto, será usada a tese de Silvio de Almeida, jurista, em sua obra Racismo Estrutural $^{1}$. Fazendo-se uso da linha argumentativa defendida por

1 Não abordaremos toda a completude desta obra do Silvio de Almeida, para este trabalho nos interessa as estruturas sociais que ele explica e como isso afeta nas demais dimensões sociais.

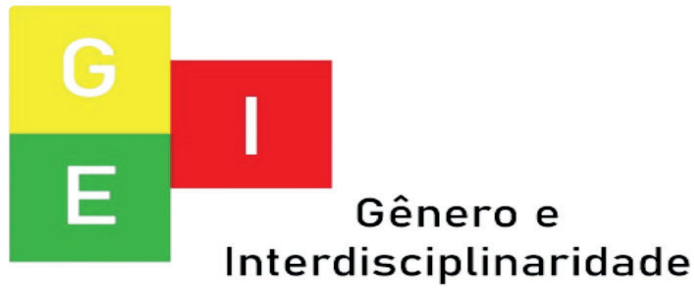


Vol. 02 - n 06 - ano 2021

Editora Acadêmica Periodicojs

Almeida, será possível concluir que as injustiças sociais também evidenciam caráter epistêmico injusto. Almeida introduz sua reflexão sobre a base histórica das injustiças sociais, para isso ele afirma que "cada sociedade possui uma trajetória singular que dará ao econômico, ao político e ao jurídicos particularidades que só podem ser apreendidas quando observadas as respectivas experiências históricas (formações sociais) (ALMEIDA, 2020, p. $55)$.

Para o presente projeto, a partir do cenário apresentado, é necessário abordar o fundo histórico que origina as bases sociais contemporâneas.

O contexto da expansão comercial burguesa e da cultura renascentista abriu as portas para a construção do moderno ideário filosófico que mais tarde transfor- maria o europeu no

homem universal

(atentar ao gênero aqui é importante) e todos os povos e culturas não condizentes com os sistemas culturais europeus em variações menos evoluídas. (ALMEIDA, 2020, p. 25)

Essa citação tem vários pontos importantes: primeiramente, é o contexto histórico de formação do europeu no homem universal; em seguida desenvolve, explicando a dominação através da expansão comercial do europeu sobre os demais povos e culturas; o terceiro, como essa dominação e elaboração de homem universal afetou as demais culturas e variações. Porém, o ponto fundamental é a criação desse conceito de homem universal e a dominação dos povos que estabeleceu um grupo identitário

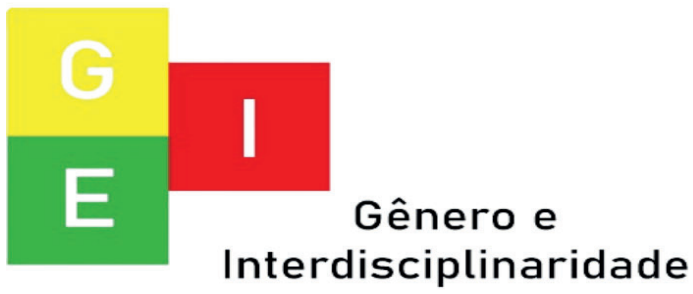


ISSN: 2675-7451

Vol. 02 - n 06 - ano 2021

Editora Acadêmica Periodicojs

como detentor do poder social, com isso, capaz de moldar as estruturas sociais. Esse grupo detentor do poder social é o grupo de homens europeus, assim, todos os outros grupos sociais, inclusive grupos europeus que não tenham as características idealizadas no homem "universal", têm seus status definidos como menos evoluídos. Esta consideração pode ser explorada para sugerir que machismo e racismo compartilham da mesma base, já que conceito de universal parte de uma concepção masculina e europeia branca. Mas, claro, o conceito de homem universal é um conjunto restrito de particularidades e não um universal.

No tocante à nossa pesquisa, essa conceitualização funda as práticas epistêmicas que Fricker demonstra serem injustas, uma vez que as ferramentas epistêmicas não são fornecidas a todos os grupos e preconceitos epistêmicos derivam desse tipo de conceitualização, a qual estrutura a norma do que é válido como conhecimento. Porém convém questionar o porquê essas bases são mantidas na contemporaneidade de modo a estruturar a sociedade?

"Assim, detêm o poder os grupos que exercem o domínio sobre a organização política e econômica da sociedade. Entretanto, a manutenção desse poder adquirido depende da capacidade do grupo dominante de institucionalizar seus interesses, impondo a toda sociedade regras, padrões de condutos e modos de racionalidade que tornem "normal" $\mathrm{e}$ "natural" o seu domínio." (ALMEIDA, 2020, p. 40)

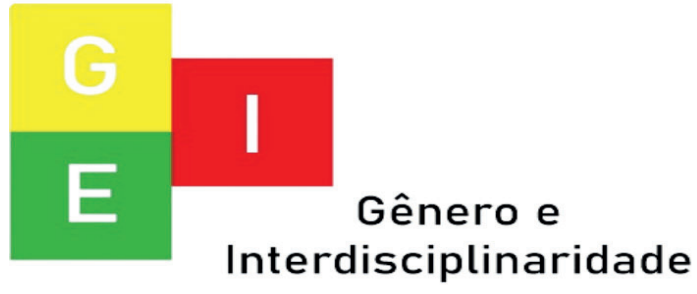


Vol. 02 - n 06 - ano 2021

Editora Acadêmica Periodicojs

Com isto, Almeida afirma que o domínio dos homens europeus em instituições implica também na reprodução de dogma, uma vez que somente seus padrões são normais e naturais, além de manter a desigualdade entre dominantes e demais grupos porque esses não conseguem ascender dentro das instituições. Então, é possível enxergar como as relações que permeiam o racismo e machismo têm uma dimensão constitutiva de poder social de um grupo sobre os outros e como esse controle é feito pelo aparato institucional. Assim, não caberia apenas dizer que as instituições são machistas e racistas, mas faz-se necessário entender os modos pelos quais racismo e machismo se dão na sociedade. Afirma Almeida:

Assim como a instituição tem sua atuação condicionada a uma estrutura social previamente existente - com todos os conflitos que lhe são inerentes -, o racismo que essa instituição venha a expressar é também parte dessa mesma estrutura. As instituições são apenas a materialização de uma estrutura social ou de um modo de socialização que tem o racismo como um de seus componentes orgânicos. Dito de modo mais direto: as instituições são racistas porque a sociedade é racista. (ALMEIDA， 2020, p. 47)

Em virtude do exposto, a reflexão deste estudo pretende apresentar um possível diálogo entre Fricker e Almeida: na teorização sobre as estruturas sociais expressas por Almeida, é possível percebermos as raízes do poder social e como este age,

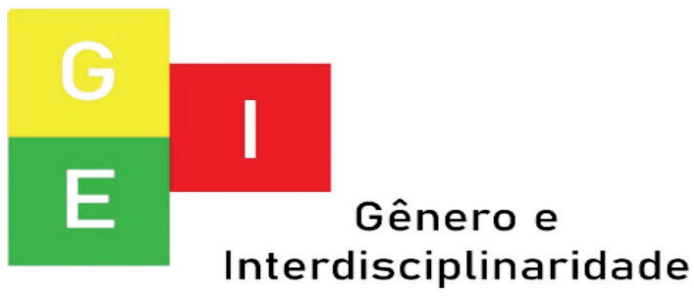


Vol. 02 - n 06 - ano 2021

Editora Acadêmica Periodicojs

sendo ele determinante para as estruturas serem injustas, inclusive em termos epistêmicos: caracterizando-se, assim, as injustiças epistêmicas teorizadas por Fricker. O jurista ressalta que as instituições são utilizadas como política de dominação e controle sobre os demais grupos para perpetuar a estrutura normativa. Com isso, grupo ditos minoritários sofrem injustiças testemunhais a partir de uma injustiça hermenêutica bem estruturada e reproduzida. Almeida deixa claro que os "comportamentos individuais e processos institucionais são derivados de uma sociedade cujo o racismo é regra e não exceção" (ALMEIDA, 2020, p. 50) , deixando evidente a injustiça hermenêutica como regra da sociedade que influencia em outros aspectos epistêmicos derivados de preconceitos. Ao passo que a norma social estabelece lacunas obstruidoras de aspectos particulares dos grupos não dominantes, isto é, faltam conceitos e ferramentas epistêmicas que os impedem de darem voz e sentido às suas vivências.

No entanto, Almeida ressalta o dever das instituições na sociedade, com a premissa de que as instituições são meios reprodutivos e de divulgação das estruturas sociais, logo, se a sociedade está em conflito sobre alguns aspectos, isso se refletirá institucionalmente. Como demonstra jurista:

a) as instituições são conflituosas e sua coesão depende da capacidade de absorver conflitos, tanto ideológica quanto repressivamente; b) a instituição precisa se reformar para se adaptar à dinâmica dos conflitos sociais, o que implica alterar suas próprias regras,

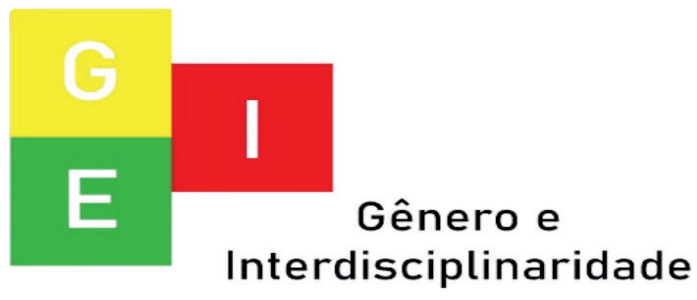


Vol. 02 - n 06 - ano 2021

Editora Acadêmica Periodicojs

padrões e mecanismos de intervenção. (ALMEIDA， 2020, p. 42)

As instituições são meios que podem alterar a estrutura social. Tal alteração tem como ponto de partida um conflito social, quando a instituição toma para si a resolução desses conflitos, institucionalizando-os e posteriormente apresentando reformas. A partir dessa resolução de conflitos sociais, a institucionalização as reproduz para os indivíduos: esse é o modo como se reforma regras e padrões que vêm a reestruturar as bases sociais. Como mencionado anteriormente, Almeida ressalta que para entender a política, o jurídico e a economia é necessário entender as relações sociais, essa é uma relação de mutualidade, pois os modos que as relações vão mudando, a economia, a políti- ca e o jurídico mudam também.

A cada mudança promovida por uma instituição, ocorre influência nas relações sociais.

A institucionalização máxima de uma sociedade e a união entre a economia, política e jurídica é o Estado. Assim, se faz necessário explanar, mesmo que brevemente, a relação entre as instituições e as relações sociais.

(I) A política se faz na relação de soberania de um povo com seu governo, para isso Almeida apresenta a reflexão de Mbembe:

a expressão máxima da soberania é a produção de normas gerais por um corpo (povo) composto por homens e mulheres livres e iguais. Esses homens e mulheres são considerados sujeitos completos, capazes de autoconhecimen-

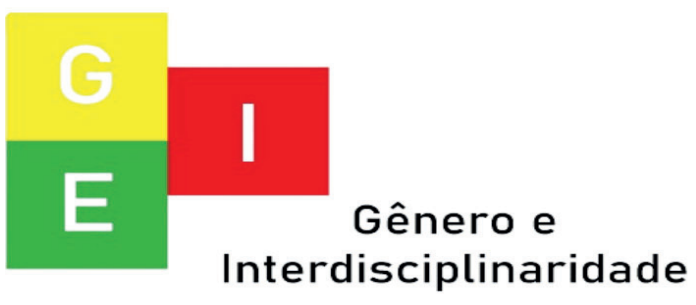


Vol. 02 - n 06 - ano 2021

Editora Acadêmica Periodicojs

to, autoconsciência e auto representação. Assim, a política se define, simultaneamente, como um projeto de autonomia e a realização de um acordo em uma coletividade, acordo esse que a filosofia política clássica denomina de contrato social. (ALMEIDA， 2020, p. 90)

(II) A relação econômica é indissociável do Estado e das relações sociais, e o sistema econômico que predomina no mundo é o sistema capitalista, isso se deve pela própria história da humanidade e do tipo de relação com o produto. Comprova-se a partir do argumento exposto por Almeida:

A sociedade capitalista tem como característica fundamental a troca mercantil. Desse modo, a existência da sociedade capitalista depende

que os indivíduos

que nela vivem relacionem-se entre si, predominantemente, como livres e iguais. Só é garantida esta condição aos indivíduos quando a troca mercantil pode se generalizar e se tornar a lógica constitutiva da sociedade. Por isso, caberá ao Estado assegurar o direito à liberdade individual, à igualdade formal (apenas perante a lei) e principalmente à propriedade privada. Sem liberdade individual, igualdade formal e propriedade não poderia haver contratos, mercado e portanto, capitalismo. (ALMEIDA, 2020, p. 92)

Dessa reflexão, o jurista já infere a relação (III) jurídica do Estado e como ela age, uma vez que o Estado, que adota o modo

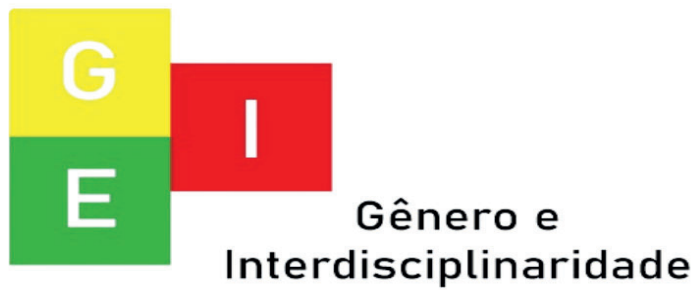


Vol. 02 - n 06 - ano 2021

Editora Acadêmica Periodicojs

capitalista em sua esfera econômica, adota uma formação que deve garantir que aconteça as relações mercantis. Para isso, é necessário que os indivíduos sejam iguais perante a lei, e o jurídico é a parte estatal que normatiza, regula as relações sociais perante a instituição do Estado, ou seja, é o jurídico que detém o poder institucional do Estado.

O jurídico é o ordenamento institucional do Estado que, como demonstrado, tem uma relação de soberania com o povo - que abre mão de parte de suas liberdades individuais em favor da vida em sociedade (contrato social) -, essa relação de soberania garante ao Estado poder sobre os indivíduos e é esse poder que concede realidade ao direito (SCHMITT, 2006), uma vez que é esse poder que dá vida às normas jurídicas, concedendo realidade ao direito.
Entender a dinâmica dessa relação jurídica, política e econômica é absolutamente essencial à compreensão do poder social, e a forma como ele é consolidado e é reproduzido. Almeida demonstra isso com a seguinte citação:

As concepções institucionalistas parecem compatíveis com o direito visto como manifestação do poder. Se o direito é produzido pelas instituições, as quais são resultantes das lutas pelo poder na sociedade, as leis são uma extensão do poder político do grupo que detém o poder institucional. $\mathrm{O}$ direito, nesse caso, é meio e não é fim; o direito é uma tecnologia de controle social utilizada para a consecução de objetivos políticos e para a correção do funcionamento institucional.

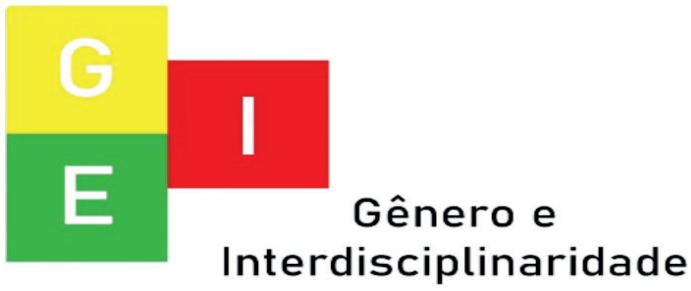


Vol. 02 - n 06 - ano 2021

Editora Acadêmica Periodicojs

(SCHMITT, 2006, p.

Por meio do exposto por Almeida, é perceptível que as estruturas sociais são injustas devido a seu contexto histórico. Entretanto, a história está em constante desenvolvimento, sendo assim, a estrutura social não é estática e se movimenta conforme o jogo social do momento, nesse jogo as instituições têm parte importante porque são elas que normatizam o que se tornará regra social. Dessa forma, o Estado, instituição de maior ordenamento jurídico, deve/necessita acatar as mudanças sociais se pretende garantir realidade ao direito.

Em síntese, a partir da História podemos constatar uma dominação do homem europeu, esse, a partir de sua dominação, utilizou dos sistemas políticos, econômicos e jurídicos para normalizar sua dominação. Essa normalização do homem europeu como sujeito "universal" gerou e gera alguns tipos de desigualdades sociais como o racismo e a violência de gênero. Essa sistemática permite afirmar que as desigualdades sociais que, têm como fundo tal normalização do "sujeito universal" e que exclui os outros grupos, são injustiças epistêmicas. Uma vez que os outros grupos (negros e mulheres) não são inclusos nesse grupo dominante, também não podem criar e deter ferramentas epistêmicas, sofrem com os preconceitos normatizados pelo grupo dominante. Podemos confirmar essa reflexão a partir de alguns tipos de injustiças sociais, e para este trabalho será especificamente utilizada a violência de gênero como panorama para apresentar o caráter epistêmico dessa injus-

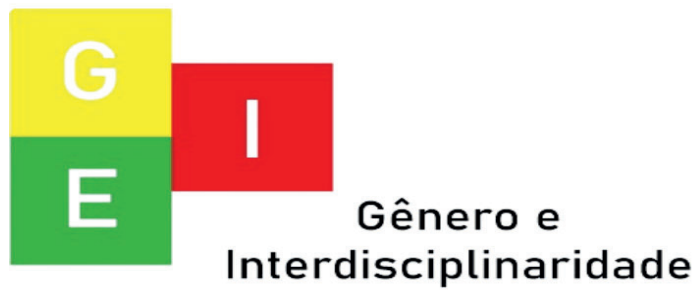


tiça.

\section{VIOLÊNCIA DE GÊNERO COMO INJUSTIÇA EPISTÊ- MICA}

Tendo em vista o apresentado, é permitido inferir que uma injustiça social está na raiz de uma injustiça epistêmica. Como exposto por Fricker, as injustiças epistêmicas têm sua origem na esfera social, ou seja, no poder social. A filósofa argumenta que por se basear no poder social, o cálculo epistêmico é injusto. O cálculo epistêmico é uma operação que estabelece credulidade e veracidade ao falante, no entanto, esta operação utiliza de conceitos e de qualificações estabelecida também pelo poder social, definindo a credibilidade de um sujeito com base não nas suas capacidades cognitivas ou intelectuais (enquanto sujeito que conhece), mas nas suas relações

e posições sociais, que são dadas pelo poder social. Ao utilizar-se das relações sociais, esse cálculo assume preconceitos em suas operações derivados do poder social. Esse cálculo é injusto porque a sociedade é injusta, os preconceitos pertencentes às operações, na maior parte das vezes, carregam preconceitos identitários que não deveriam ter implicações epistêmicas, uma vez que esses preconceitos contenham vieses ideológicos de cunho social utilizados para dominação e controle social, conforme argumentado por Almeida.

Assim também como apresentado no tópico de Almeida, pode-se perceber o entrelaçamento de suas ideias com as de Fricker, uma vez que ambos têm em consonância o mesmo alicerce estrutural e têm a mesma solução defendida: a necessidade

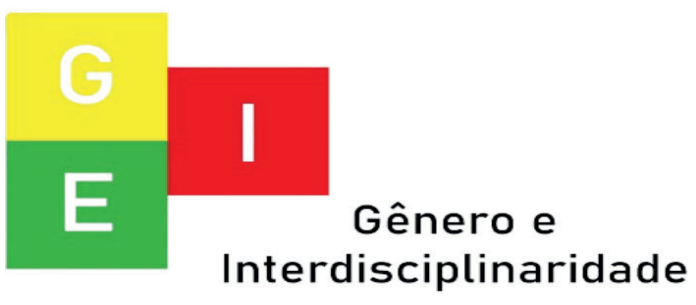


Vol. 02 - n 06 - ano 2021

Editora Acadêmica Periodicojs

de mudança institucionalizada de cunho ético-política. No argumento de Almeida é constatado o eixo estrutural das injustiças sociais e como esse é dominante e auto reprodutor, influenciando todas as vertentes sociais e presentes nas práticas epistêmicas, como constatado por Fricker.

\section{CONCLUSÃO}

A partir dos argumentos apresentados é possível inferir que a influência do gênero nos cálculos e relações epistêmicas é determinante para uma injustiça epistêmica. Uma vez que pode descredibilizar ou atribuir uma credibilidade em excesso ao falante/conhecedor, e de forma estrutural é um fator utilizado para dominação e reprodução social e assim não fornece ferramentas epistêmicas para esses grupos marginalizados - o não-homem europeu. Entretanto, o gênero pode ser utilizado de forma benéfica nos cálculos epistêmicos através de ouvintes virtuosos e ações institucionais que resultem em virtudes epistêmicas e corrijam/preencham as injustiças estruturais em suas lacunas.

\section{REFERÊNCIAS}

ALMEIDA, S. L. D. Racismo Estrutural. 6. ed. São Paulo: Jandaíra, 2020.

FRICKER, M. Epistemic Injustice: Power and the Ethics of Knowing. Tradução de tradução minha. primeira. ed. New York: Oxford University Press, v. único, 2007.

KUHNEN，T. FRICKER，Miranda. Epistemic Injustice: Power and the Ethics of Knowing. Periodico UFSC, Florianópolis,

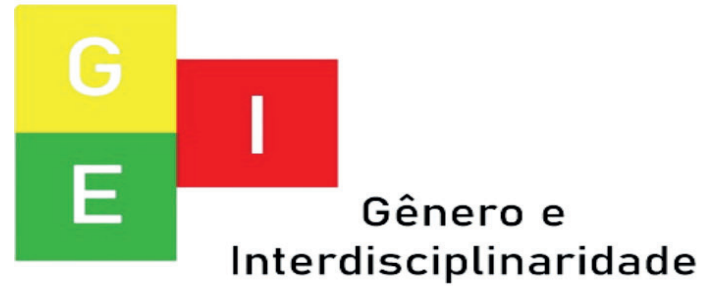


Vol. 02 - n 06 - ano 2021

Editora Acadêmica Periodicojs

2013. 627.

LUZ, A. M. Conhecimento e justificação: problemas de epistemologia contemporânea. 1. ed. Pelotas: Dissertatio Filosofia, v. Único, 2013.

RUSSELL, B. The Problems of Philosophy. Tradução de Jaimir Conte. 7. ed. Oxford: Oxford University Press paperback, v. Único, 1912. Disponivel em: <https:// conte.prof.ufsc.br/txt-russell. pdf $>$. Acesso em: 11 jul. 2021.

SHKLAR, J. The Faces of Injustice. Integral. ed. Yale: Yale University Press, v. Único, 1990.

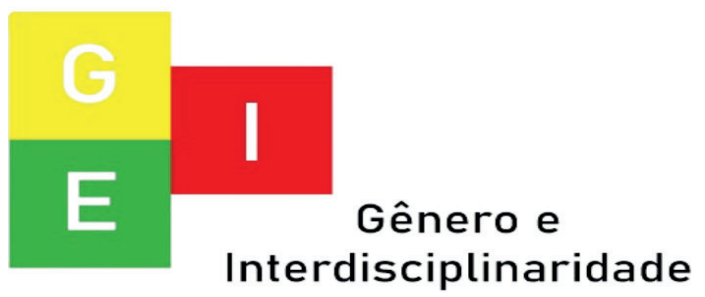

